\title{
Eupsychian Theory: Reclaiming Maslow and Rejecting The Pyramid - The Seven Essential Needs
}

\author{
Dr. Mike Sosteric \\ Athabasca University \\ mikes@thabascau.ca,
}

Gina Ratkovic

Athabasca University

Version 1.25 


\begin{abstract}
In 1943, Abraham Maslow presented a now widely accepted theory of human motivation. This theory was shortly represented by a now iconic Pyramid of Needs. Building upon the work of Abraham Maslow, this article rejects the pyramid of needs as an ideologically rooted, sanitized, and stripped-down version of Maslow's nascent Eupsychian Theory. Instead, the article proposes a Circle of Seven Essential needs as the core of a sophisticated and integrative humanistic/transpersonal Euspychian theory of human development and human potential, a theory that Maslow was in the process of developing before his untimely death. As argued in the article, the Circle of Seven Essential Needs encourages us to develop a broad, holistic, and integrative view of human nature, human development and the role of human society more in line with Maslow's thinking on human development and human potential.
\end{abstract}


Why has the hierarchy of needs been so popular? The appeal of the pyramid image should not be underestimated, especially to those of us in the United States. We the people are fond of ranking everything, from cities to graduate programs to football; teams to the jokes in David Letterman's lists. "Maslow" might have chosen a different icon (e.g., a Native American medicine wheel) but it would not have had the same iconic appeal (Peterson \& Park, 2010, p. 30: scare quotes added).

As I have gained knowledge and seen others share their visions with me, I conclude that our ancestors lived in a strange condition in which they were in touch with the spirits constantly, and I see that as a goal for our present activities. Vine Deloria (2003, p. xvii). 


\section{The Hierarchy of Needs}

Anyone who has ever bought a book in the self-help corner of their local bookstore, anyone who has ever taken a psychology class in university, anyone interested in management theories, or students of human resources, any analysts of organizations, indeed, anybody concerned in any way with human labour, human behaviour, and human potential will be familiar with Abraham Maslow's theory of human motivation, his hierarchy of needs, and the iconic pyramid which has come to define it. His original article is a perpetually cited piece (Kuo-Shu Yang, 2003) that continues to appear in textbooks on psychology, leadership, sociology, medicine, education, management, marketing, and organizational behaviour (McCleskey \& Ruddell, 2020). His original theory continues to be deployed by psychologists, management theorists, human resource employees, and others to understand and explain human behaviour and motivation (Anburaj Balraj, 2017; Crandall et al., 2020; Jie Guo et al., 2019; Lussier, 2019; Poirier \& Devraj, 2019). It is no overstatement to say that the theory is one of the "most impactful theories" in psychology and personality research (Christian Montag et al., 2020).

What has made Maslow's theory so “widely distributed, incredibly popular, and largely accepted?” (McCleskey \& Ruddell, 2020, pp. 6-7). In original form (A. H. Maslow, 1943a, 1943b), it is a simple theory that suggests that humans are motivated by a set of five basic needs,

these being the physiological, safety/security, belonging/unconditional love, esteem, and selfactualization needs. In Maslow's theory, lower physiological and security needs were placed on the bottom of a hierarchy of prepotency, meaning lower needs, like the physiological needs for food and safety, tend to be given priority over other needs when not satisfied (A. H. Maslow, 1943a, p. 373). 
Although Maslow's theory has, since the very early days, been represented by a pyramid, it is notable that Maslow never represented his theory in this, or any, geometric form (Bridgman et al., 2019). The closest Maslow came to suggesting a geometric symbol was his use of a metaphor of nested boxes to describe the complex constellation of human needs (A. H. Maslow, 1943b). The pyramid, represented below, was a business invention, appearing first in a business magazine (McDermid, 1960) where it replaced alternative geometrical representations being discussed at the time, like steps (Davis, 1957) and ladders (Wren, 1972).

\section{The Hierarchy of Needs}

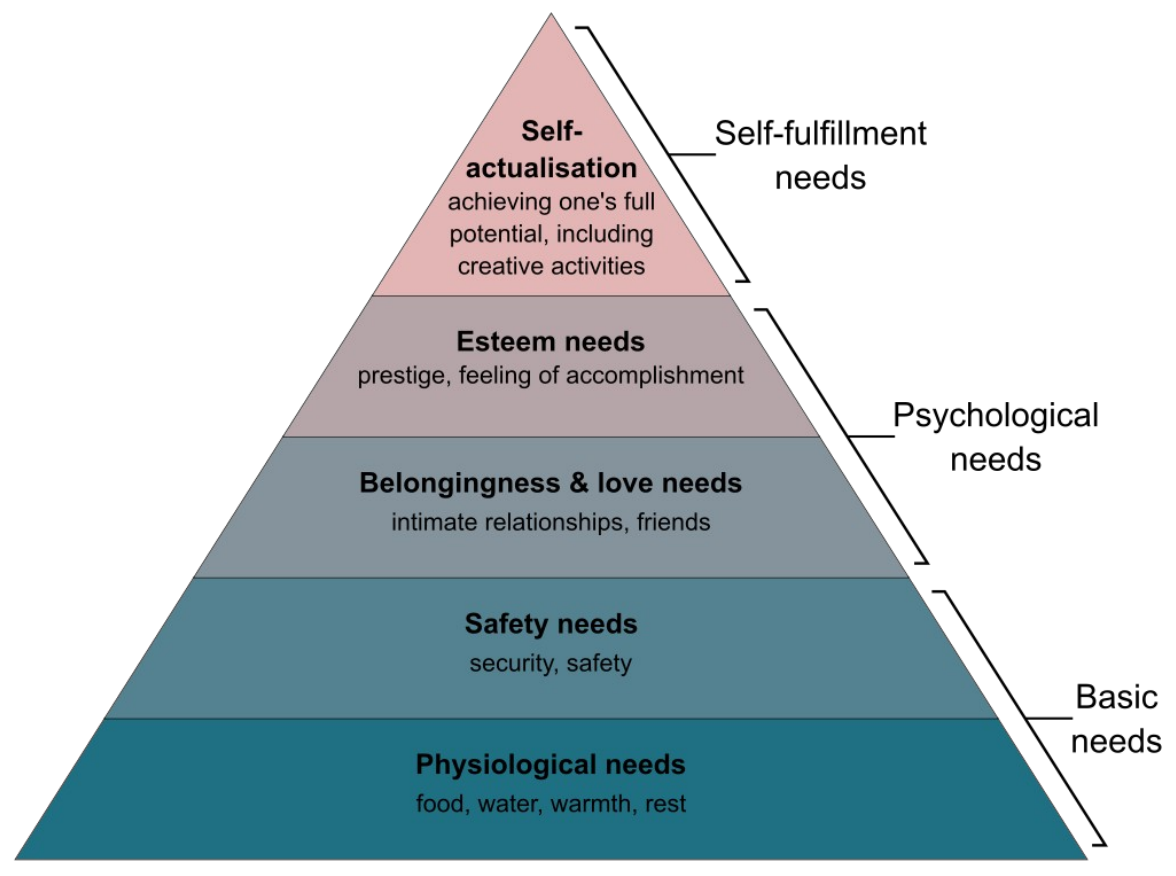

Desite the fact that Maslow neither suggested nor supported his theory with a pyramid, nevertheless, this pyramid has become an iconic representation of human needs and human motivation. This viral spread of Maslow's hierarchy and the emergence of the iconic pyramid has occurred despite the fact his conceptualization, or at least how it has been presented, has 
numerous deficiencies (Neher, 1991). It has been criticized for being internally inconsistent (Bouzenita \& Boulanouar, 2016), empirically weak (Soper et al., 1995), ethnocentric (Townsend \& Wrathall, 1997), sexist (Nicholson, 2001), and elitist (Aron, 1977). Some have suggested, quite correctly, that it is a form of western cultural and scientific hegemony (Bouzenita \& Boulanouar, 2016) that privileges "individuality" and "individual improvement" over more family-oriented, socially embedded, collectivist needs and values (Kuo-Shu Yang, 2003). Others have suggested it has a neo-liberal bias, pointing out that the theory ignores social, political, and economic conditions that might facilitate or impeded needs satisfaction, and instead relying for improvement "more on personal growth than on social reform." (Aron, 1977, p. 13).

As valid as all these criticisms appear to be, we need to be aware that many of these criticisms are levelled not at Maslow's theory per se, but at the pyramidal misrepresentation and sanitization of the theory provided by management publications. To be sure, Maslow's thought does show the imprint of a North American individualism. However, Maslow was critical of Capitalism even in the very early days of his education (Edward Hoffman, 1999). His theory, as shallow and unsophisticated as some critics have suggested it is, is actually more progressive, critical, and sophisticated, especially in later form, than the original pyramid of needs suggests. This is easy to see once we disconnect Maslow's theory from the pyramid. When we do that, we notice several remarkable things.

\section{Deconstructing “Maslow's” Pyramid}

The first thing we notice when we stop looking at the pyramid is that Maslow's understanding of human needs and motivation was more nuanced and progressive than implied by the pyramid, even in his 1943 article. Maslow was not insensitive to culture or the 
environment. Although he believed that cross-culturally all humans had the same basic needs, he made "no claim" that his theory was "ultimate or universal for all cultures" (A. H. Maslow, 1943a, p. 390). As he said, "Any theory of motivation must of course take account of ...the role of cultural" (A. H. Maslow, 1943b, p. 90, 1970, p. 28). He also understood multicultural nuances when he said that "There are usually available various cultural paths to the same goal" (A. H. Maslow, 1943a, p. 370). He was not inflexible in his conceptualization of needs satisfaction either. He clearly understood that even though some needs might, at times, take a general priority over others, nevertheless, needs were interdependent and fluid: "no need or drive can be treated as if it were isolated or discrete; every drive is related to the state of satisfaction or dissatisfaction of other drives" (A. H. Maslow, 1943a, p. 370). Maslow also understood that there were individual differences in how needs were arrayed, suggesting that individuals may prioritize needs satisfaction based on past experiences of satiation or deprivation, personal preferences, and so on ((A. H. Maslow, 1943b, 1954, 1968a). He never suggested a ridged pyramidal representation and clearly rejected a "step-wise, all-or-none" relationship of needs, noting that "normal" people "are partially satisfied in all their basic needs and partially unsatisfied in all their basic needs at the same time" (A. H. Maslow, 1943a, p. 388). Essentially, he downplayed the hierarchy. As he said, "We have spoken so far as if this hierarchy were a fixed order but actually it is not nearly as rigid as we may have implied" (A. H. Maslow, 1943a, p. 386).

The second thing we notice when we put aside "Maslow's" pyramid is that Maslow had more to say about basic needs in his original article than what is represented in the basic pyramid. Typical representations of Maslow's theory overlook a second hierarchy of needs articulated in his seminal article. In this second hierarchy, Maslow placed two critical needs, the 
need to know and the need to understand. Maslow defined the need to know as the need to "be aware of reality, to get the facts, to satisfy curiosity...to see rather than to be blind" (A. H. Maslow, 1943a, p. 385). Maslow defined the need to understand as the need to understand the reality that we came to know. According to Maslow, it was not enough just to know things, to accumulate mere facts. As he said, "...the facts that we acquire, if they are isolated or atomistic, inevitably get theorized about, and either analyzed or organized or both” (A. H. Maslow, 1943a). Maslow felt the need to know and understand where driving needs. As he said, "even after we know, we are impelled to know more and more minutely and microscopically on the one hand, and on the other, more and more extensively in the direction of a world philosophy, religion, etc" (A. H. Maslow, 1943a, p. 385). Maslow also thought these cognitive needs might be placed in their own hierarchy. "Once these desires are accepted for discussion, we see that they too form themselves into a small hierarchy in which the desire to know is prepotent over the desire to understand" (A. H. Maslow, 1943a, p. 385). Note that Maslow was ambivalent about separating them into a second hierarchy. "We must guard ourselves against the too easy tendency to separate these desires from the basic needs... i.e., to make a sharp dichotomy between 'cognitive' and 'conative' needs. The desire to know and to understand are themselves conative, i.e., have a striving character, and are as much personality needs as the 'basic needs' we have already discussed" (A. H. Maslow, 1943a, p. 385).

Finally, a third thing we notice when we look beyond the pyramid is that Maslow's thinking evolved. In later years, he tempered his elitism. Initially, he had suggested that only a few people could self-actualize and only a few had peak experiences. Later on, he realized that everyone had the potential to grow and that all but the most psychologically damaged could have these 
experiences (Sosteric, 2018a). As his thinking progressed, he also added other needs to his theory, like aesthetic needs (A. H. Maslow, 1954) and the need for transcendence (KoltkoRivera, 2006), both of which he considered very important. Consider transcendence. Although he struggled with the concept (A. H. Maslow, 1969), nevertheless he set it at the core of his theory of needs. As he says in his notebook on Eupsychian management, "We must ultimately assume at the highest theoretical levels of eupsychian theory, a preference or a tendency to identify with more and more of the world, moving toward the ultimate of mysticism, a fusion with the world, or peak experience, cosmic consciousness, and so on" (Abraham H. Maslow, 1965, p. 33: emphasis added).

At this point, we can see the problem. Not only is Maslow's pyramid not Maslow's pyramid, but it is not even Maslow's theory. It is a simplified, sanitized, and ossified version that misrepresents even his early thinking and fails to take into account the maturation of his views. The questions here become, why was this pyramid accepted in the first place and why is it still in place? The question is particularly salient given there have been attempts to revise the model with "architectural extensions" and alternative geometric representations (Bridgman et al., 2019; Heylighen, 1992; Kenrick et al., 2010; Kuo-Shu Yang, 2003; Nevis, 1983), yet none of these stick.

Several reasons have been identified for the persistence of a stripped-down version of Maslow's theory despite perceived failings. Maslow himself recognized extant resistance and suggested this resistance was the outcome of a scholarly pathology that created depressed, cynical, malicious, cruel, and vengeful members "of the intellectual community" who used their control of the channels of communication to the educated public and to youth" (A. H. Maslow, 
1970, p. x) to suppress his theory. Some have suggested that user-friendly packaging (Lussier, 2019), face validity (Buttle, 1989), and basic explanatory value (Loh et al., 2000), at least when applied with broad brush strokes (Peterson \& Park, 2010), keep the theory on the table. Others suggest it remains because it is "usable" (Loh et al., 2000). As some have noted (Lussier, 2019), Maslow's theory provides actionable information to marketers and management seeking to understand and manipulate human behaviour and justify an exploitative system (Soper et al., 1995). Maslow's theory gives marketers a theoretical framework that allows them to conceptualize and effectively market products as capable of satisfying human needs (Peterson \& Park, 2010, p. 320). It also gives management information they can use to organize and present their corporations as spaces where human needs can be met, not as such, but as a way of motivating employees, attaching them to the organization, and justifying an otherwise exploitative workplace (Bridgman et al., 2019; Lussier, 2019, p. 319). As Lussier (2019, p. 320) notes, applying Maslow's theory in organizations was useful as a means of countering "charges that corporations entailed numbing rationalization and standardization of individuals, these management approaches draw on the hierarchy of needs to describe work as a site for selfactualization, personal fulfillment, and even pleasure." As Bridgman et al. too gently put it (2019, p. 90), "Following World War II, Maslow's [hierarchy of needs] captured the prevailing ideologies of individualism, nationalism, and capitalism in America and justified a growing managerialism...." Also note that the pyramid itself is a visual replica of Capitalist class hierarchies, a replica completely concordant with Neo-liberal discourse, thereby providing powerful and useful confirmation of Capitalist hierarchies and the presumed distribution of human talent, ability, and reward. In this context, the pyramid constitutes an individual who 
defines psychological health as individual achievement and "self" actualization. This focus on the "achieving self" is useful for Capitalist organizations seeking to exploit human creative effort and labour. In this way, the pyramid provides a gloss over the violence and exploitation required for the System to operate unabated, by presenting human nature and human motivation as completely compatible by a salutatory Capitalist regime.

Beyond providing actionable Intel and supportive ideology, it may also be the case that there has been psychological and ontological resistance (Habib, 1993) to Maslow's more progressive and sophisticated statements. Ontologically, although Maslow repeatedly insisted upon the instinctoid root of transcendence, nevertheless, some of Maslow's later statements move into the uncomfortable (for some) realm of human spirituality. Materialists may resist looking at his more spiritual statements. Psychologically, there may be a sense in which ignoring key aspects of Maslow's theory (i.e., cognitive needs, transcendence, etc.) helps those involved in the manipulation of human behaviour assuage guilt, shame, and disjuncture that would naturally arise from critical awareness of practices based on duplicity and deception. Consider Maslow's statements regarding Eupsychian management policy where he says that an enlightened organization would be one that would help satisfy an individual's need to know and understand by informing everyone "as completely as possible of as many facts and truths as possible, i.e., everything relevant to the situation" (Abraham H. Maslow, 1965, p. 17: italics in original). We can imagine how uncomfortable this requirement might make management whose primary task is manipulating human motivation in the interest of organizational productivity, or marketers, who regularly lie to consumers in the interest of selling more products. Overlooking the existence of critical cognitive needs allows one to avoid ethical discomfort (i.e., guilt, and 
shame) since it allows those whose jobs require manipulation and deception to avoid the inevitable conclusion that their practices, and indeed the entire system, are repressive, oppressive, duplicitous, and undermining of human development.

So, where do we go from here? It is possible to eject Maslow's theory out of hand and replace it with something more modern. Beyond the fact that doing that means rebuilding from scratch, there are good reasons not to simply jettison Maslow's work. Maslow's initial statements may have presented a mere theory of motivation; however, from the very start, he was interested in much more than that. Maslow had a vision in 1940 for a Utopian psychology of the "peace table" (E. Hoffman, 1999, p. 137), an advanced psychology that would provide a "Hierarchical-Integrative Theory of Needs," (A. H. Maslow, 1970, p. xvi), a Eupsychian theory (Abraham H. Maslow, 1965) with "utopian ends" (Dewsbury et al., 2012, p. 257) that he felt would form the foundation of a psychology that would "speak to human potential and wholeness (Ballard, 2006, p. 2) and that would provide normative and prescriptive suggestions towards the development of a "way of life, not only for the person himself within his own private psyche, but also for the same person as a social being, a member of society" (A. H. Maslow, 1968a, p. iii). $\mathrm{He}$, and others, were developing a psychology that provided a "new image of man [sic]" (A. H. Maslow, 1970, p. x), one that acknowledged our inherent goodness and that prioritized the development of healthy and fulfilled human beings (A. Maslow, 1961) motivated by higher needs (A. H. Maslow, 1967). His two primary statements of this are in his books Motivation and Personality and Towards a Psychology of Being, both of which provide pieces of a much "larger theoretical structure" (A. H. Maslow, 1968a, p. vii) than is represented by the iconic five-level pyramid. 
This larger theoretical structure was part of a new psychology that would include humanistic psychology and a "higher Fourth Psychology" (i.e. Transpersonal Psychology) focussing on humanity's relationship to "the cosmos." Maslow felt this new psychology would help resacralize an arid and dehumanized science (Abraham H Maslow, 1966). The new psychology would include a Eupsychian Theory aimed at creating a eupsychian society, i.e. a good society that would create happy, fully developed humans. The Eupsychian theory would provide new systems of meaning where religion has so thoroughly failed (A. H. Maslow, 1964) and would contribute to a reconceptualizaton of "every area of human knowledge: e.g., economics, sociology, biology, and every profession: e.g., the family, education, religion, etc." (A. H. Maslow, 1970, p. x). He was explicit about his goals (A. H. Maslow, 1968a) and active in developing curriculum (A. H. Maslow, 1968b). He was also clear that even though the work that had been done as of 1970 was only the "bare beginning" (A. H. Maslow, 1970, p. xxi), nevertheless progress had been made. In 1969 he writes that "There is now available a new conception, of a higher possibility, of the healthy society. There are tools now available to judge and compare societies. One society can be judged to be better than another society, or healthier or possessing more 'growth-fostering-potential.' We can talk about the value of the society, or the function of the society-that is, the greatest coming to fulfillment of the people in the society" (Maslow, A. H., 1969, p. 7). Interestingly, Maslow even had a model for his Eupsychia, though he perhaps did not make as much of it as he could have. In 1938, he visited a Blackfoot tribe in Alberta, Canada, a visit that had a massive impact on his thinking (Blackstock, 2011). Following that visit, he concluded that Blackfoot society was superior to North American society, at least in terms of its ability to support self-actualization. "Members of the Blackfoot tribe displayed high 
levels of emotional security, and thus were more self-actualized than the industrial capitalist and settler in North American society. Because basic needs were provided for...the Blackfoot were able to embody emotional security and self-actualization in higher levels than in mainstream North American society" (Lussier, 2019).

If it is true that Maslow made significant progress towards developing a eupsychian theory but that, for various reasons, this deeper theory was ignored or suppressed, it is reasonable to suggest we need a recovery effort; but, where to start? We think the best place to start is by ejecting the ideological pyramid and replacing it with something more aligned with Maslow's own thinking. We suggest not steps, ladders, nested boxes, or pyramids, but a circle with modified categories. As we will see, the circle helps us break out of the Neo-liberal conditioning present in the pyramid and better represents the essence of Maslow's "profoundly holistic" (A. H. Maslow, 1970, p. ix) theory, a theory which, from the very start, saw humans as an “integrated, organized whole" (A. H. Maslow, 1943b, p. 85).

We would like to note that although we came up with the conceptualization of a circle independently, Indigenous thinkers have proposed a circular representation (Blackstock, 2011; Cross, 2007). It should be stated here that the co-author of this paper is an Indigenous member of the Carry the Kettle Nakoda First Nation in Saskatchewan, Canada. With that, we present the Circle of Seven Essential Needs. In order to contextualize the circle in a Eupsychian Theory, we provide a basic theoretical introduction in the form of several itemized statements. 


\section{The Seven Essential Needs}

\section{SEVEN ESSENTIAL NEEDS}

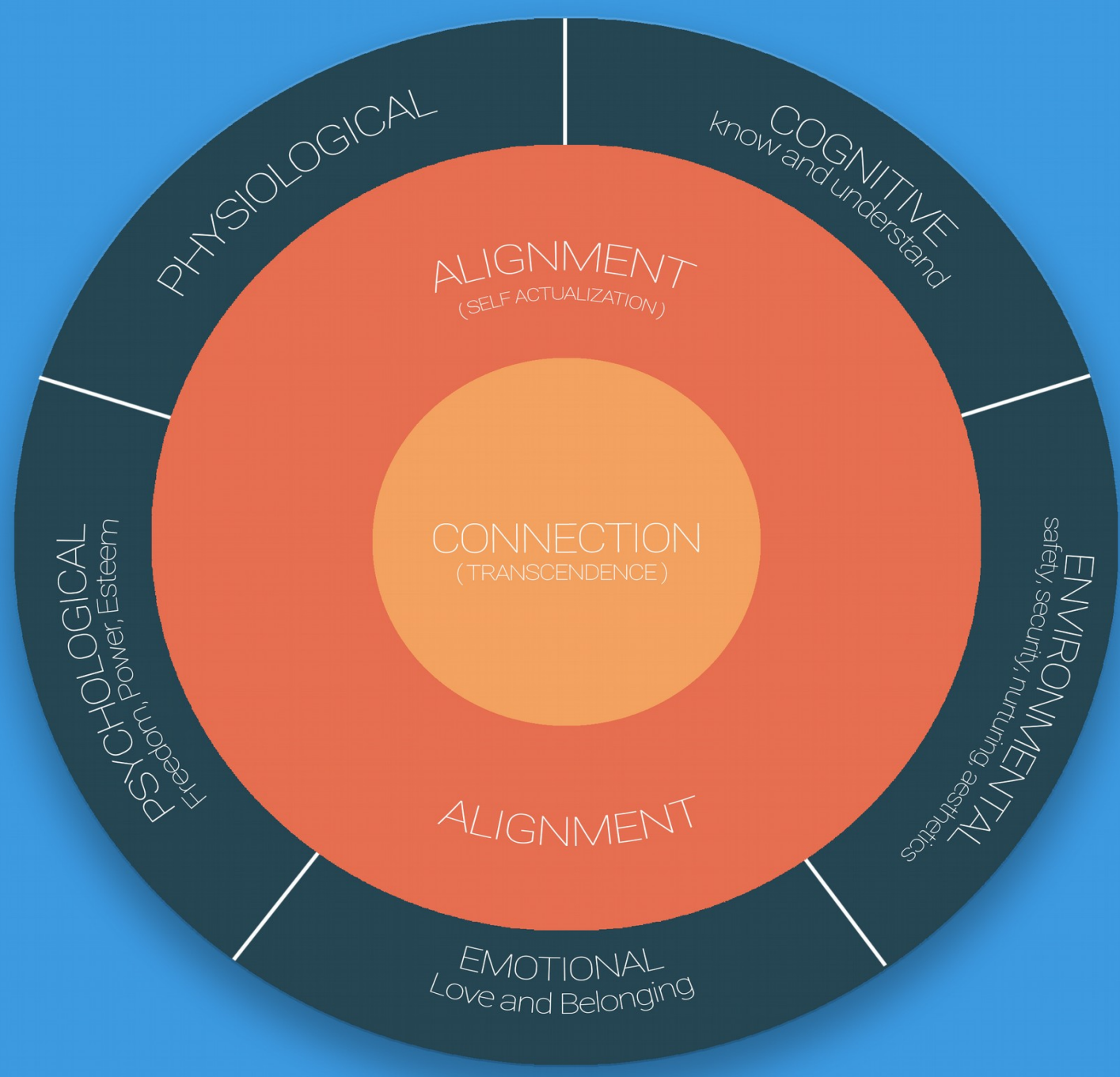


1. We start our contextualization by noting we replace the phrase "hierarchy of needs" with the phrase "essential needs." We also note that we organize essential needs into three layers. Essential needs include the basic needs (outer circle) and also the core inner circle needs of alignment and connection. This circular arrangement reflects the basic eupsychian notion that in order for humans to be healthy, happy, and fully developed, all their essential needs must be met. As Maslow clearly indicated, "self-actualizing people are gratified in all their basic needs" (A. H. Maslow, 1967, p. 93) and the healthiest people are those who self actualize and transcend (A. H. Maslow, 1968a, 2012). Note, this does not mean that all needs must be fully gratified, a state of affairs that Maslow considered impossible (A. H. Maslow, 1943a, p. 388), only that they be "relatively well gratified" (A. H. Maslow, 1970, p. 39). What counts as relatively well gratified may differ based on personal predilections, cultural stipulations and other factors, and is a question for empirical investigation.

\section{The basic needs in the outer circle are reformulated from Maslow's original into} more generic and flexible categories that we feel better capture the full gamut of human need and the essence of Maslow's thinking. We retain Maslow's original categories of physiological needs but place safety and security needs into the category of environmental needs, love and belonging into the category of emotional needs, and needs for freedom, self-esteem, and power into the category of psychological needs. We also include Maslow's cognitive needs in the basic circle. All told, the basic needs include five sets of needs, the physiological, cognitive, emotional, psychological, and environmental needs. 
1. Physiological Needs - Physiological needs include the need for substances (like food, water, vitamins, air), the need for physical activity (exercise), the biological drives for sex, and so on. Meeting physiological needs keeps the body healthy and growing.

2. Environmental Needs - Maslow's original theorization included needs for safety and security; in other words, a safe and secure environment. We reconceptualize these needs as environmental needs. We include in this category the need for a safe and secure environment but go further and include the need for protective, nurturing, and aesthetically pleasing environments at home, work, and everywhere. Note that safety includes the absence of assault of any kind, including physical assault (e.g., spanking, pushing, slamming objects, shaking etc.), emotional and psychological assault (screaming, name-calling, racism, sexism, shaming, passive aggressive assaults) (A. H. Maslow, 1954, p. 40). Stability includes financial stability, which removes anxiety about work and survival, but also the emotional and psychological consistency of emotionally and psychologically stable parents and stable familial relationships. Sufficient environments are environments free of chaos and uncertainty, where all essential needs are met. There is sufficient evidence to assert that safe, calm, stable, and nurturing environments are a prerequisite to psychological health, well-being, and growth, and that lack said environments leads to various forms of distress and disease (Sosteric \& Ratkovic, 2016). Ultimately, we need an environment that is safe, nurturing, secure, calm, aesthetic and that encourages "free, uninhibited, 
uncontrolled, trusting, unpremeditated expression of the self " (A. H. Maslow, 1967, p. 197) and the expression of "pure spontaneity."

3. Cognitive Needs - Cognitive needs include our need to know and understand the world. Our human needs to know and understand are self-evident. We see these expressed in children as soon as they begin to talk and ask questions. In healthy individuals, these needs are impossible to satiate. Healthy growth requires continuous learning.

4. Emotional Needs - As per Maslow, emotional needs include our "love and belonging needs." Emotional needs also include our need for unconditional love, support, acceptance, and inclusion in family, friend groups, and society. Maslow indicated these needs are no less important for physical health and well being than physiological needs, further underlining the need to jettison a hierarchical representation of needs. As he said, "No psychological health is possible unless this essential core of the person is fundamentally accepted, loved and respected by others and by himself" (A. H. Maslow, 1968a, p. 196).

5. Psychological Needs - Maslow's original theory included esteem needs. According to Maslow, esteem needs contain two subsidiary sets of needs, "these are, first, the desire-for strength, for achievement, for adequacy, for confidence in the face of the world, and for independence and freedom. Secondly, we have what we may call the desire for reputation or prestige (defining it as respect or esteem from other people), recognition, attention, importance or appreciation" (A. H. Maslow, 1943a, pp. 381$382)$. 
We reconceptualize these esteem needs as psychological needs. In the category of psychological needs, we include, in addition to esteem, the need for power and the need for freedom. Personal power and freedom were clearly on Maslow's radar. As he says, "Such conditions as freedom to speak, freedom to do what one wishes so long as no harm is done to others, freedom to express oneself, freedom to investigate and seek forinformation, freedom to defend oneself, justice, fairness, honesty, orderliness in the group are examples of such preconditions for basic need satisfactions" (A. H. Maslow, 1970, p. 47); however, he appears to have conflated esteem needs with power and freedom needs. To clarify, we would define the need for power as the phenomenological sense that one can change the world in accord with one's desires. As Maslow said, power is "the feeling of having some control over fate, of not being a helpless tool, a passive object, a cork on the wave which is tossed here and there by forces out of control" (A. Maslow, 1961, p. 2). Freedom is the need to explore, grow, and develop in line with one's preferences and predilections. As Maslow says, we need to be free in environments where permission is granted "to gratify and to express" (A. H. Maslow, 1970, p. 276). In order to be in a healthy psychological space, we need to feel confident in our abilities and have the power and freedom to grow and learn in line with our own needs and any community predilections.

We separate power and freedom because, in some cases, freedom is supported by other individuals and not necessarily a function of personal power. Protective parents who monitor the environment for threats provide children with the freedom they need 
to explore, that they would not otherwise have. Overly controlling parents thwart a child's abilities to express and experience freedom.

6. Within the outer circle of basic needs are two inner circles. The first inner circle is self-actualization, which we rename as a need for alignment. By alignment, we mean alignment with the inner self (actualization of one's inner self, as per Maslow) but also alignment with what is right and proper in all areas of life. One aligns with one's community, one's ancestors, with ethical and moral systems of right thought, right action, and so on. Note that alignment requires strong self-esteem and a strong sense of power and autonomy, since alignment often involves the ability to stay centered and aligned in various settings, like marketing firms, the military, exploitative workplaces, etc., which may not be supportive of alignment.

Although we feel self-actualization does, in fact, reflect a part of a real process of actualizing/aligning with one's "essential biologically based inner nature..." (A. H. Maslow, 1968a, p. 3), alignment is a better term for a few different reasons.

For one, it is culturally neutral, whereas Maslow's terms self-actualization is not, despite his claims (A. H. Maslow, 1968a, p. vi). The term "self-actualization" may imply an individuality that has more to do with the biases of Western civilization and the labour force requirements of Western Capitalism than what is actually inside needing to be actualized.

A second reason for the renaming is that alignment allows us to decenter the individualized self as the locus of full development and instead develop broader 
understandings of what the "ideal, authentic, or perfect godlike human being" (A. H. Maslow, 1968a, p. 11) might be. This all becomes important when we examine the final need, which is more about, or at least equally about, breaking down the boundaries of self and connecting with a wider reality than it is about "transcendence."

A third reason the term alignment is better self-actualization is that alignment is a nod in the direction of spiritual traditions like Christianity (St. Teresa of Avila, 2007), Islam (Boyce, 1996; Mernissi, 1991), Buddhism (Bodhi, 2005), Zen (Suzuki, 1994), Indigenous spiritualities (Broker, 1983; Lawlor, 1991), and certain spiritually oriented authors (Blavatsky, 1889; Bourgeault, 2015; Bucke, 2009; Carpenter, 1921; Ikbal, 2000; Philo of Alexandira, 2014; Swedenborg, 2016; Tolstoy, 2016), all of whom emphasize high morality, ethics, truth, just action, righteousness, compassion, authenticity, equality, alignment, and being "true to our inner nature," (A. H. Maslow, 1968a, p. 7) not only as things (metamotivations/b-values) that emerge out of selfactualization and connection, as Maslow suggested, but as prerequisites to transcendence/connection. Maslow captures this normative aspect of alignment with his statements about "intrinsic conscience" (A. H. Maslow, 1968a, p. 7) and his comments on the "bodhisattvic path" (A. H. Maslow, 1964), both of which point in the direction alignment as a prerequisite, component, and outcome of human development.

Finally, renaming self-actualization to alignment provides an avenue for opening up a productive dialog between science and human spirituality, something that Maslow 
said was a feature of fourth-wave psychology's respiritualizing of science (Maslow, A. H., 1969, p. 5). The resacrilization of science and the opening up of a dialog between science and the spiritual side of life is something that authors have repeatedly called for over the years (Griffen, 1988; Laszlo, 2006; A. H. Maslow, 1964).

7. Finally, we have the inner circle or core of the human being--transcendence, or connection as we rename it. We rename transcendence to connection not only because the term trasnscendence is culturally, psychologically, and emotionally loaded (A. H. Maslow, 1969), but because transcendence itself is better understood as a step on the road to better connection, and not the actual endpoint. One transcends ideology, "enculturation," "deficits," psychological trauma, the ego (A. H. Maslow, 1968a, p. 37), emotional blockage, and so on, in order to heal, strengthen and establish connection with "something more" than the atomistic ego. As Maslow says, when "the distinction between self and not-self has broken down (or has been transcended) [there is now] less differentiation between the world and the person because he has incorporated into himself part of the world...His self has enlarged enough to include his child. Hurt his child and you hurt him....[he has fused] with the non-self..[which includes]...not only...the world of nature...[but] other humans beings...[to the point that]...'selves overlap" (A. H. Maslow, 1967, p. 103).

Note that reconceptualizing transcendence to connection is more in line with traditional cultures, shamanic practices, Catholic mysticism, Aboriginal dream times, and research on modern mystical experiences, all of which indicate transcendence means 
transcendence of cultural, psychological, and emotional limitations in order to establish connection not only to other human beings, nature, and the cosmos, but even to divine union with "God” (Ernst, 1997; Kalisch, 2006; St. Teresa of Avila, 2007; Steeman, 1975; Underhill, 2002) or a "transcendental order." Evelyn Underhill points directly to this need when she says that we have an "innate tendency...towards complete harmony with the transcendental order, whatever the theological formula under which that order is understood" (Underhill, 2002). William James reflects the notions of alignment and connection perfectly when he says "Were one asked to characterize the life of religion in the broadest and most general terms possible, one might say that it consists of the belief that there is an unseen order, and that our supreme good lies in harmoniously adjusting ourselves thereto" (James, 1982, p. 53).

We realize there may be objections to including the concept of "spirit," which we would simply conceptualize as consciousness independent of physical matter, in the discussion. If one is not prepared to take seriously what humans have known about and experienced for thousands and thousands of years, i.e., that there are realms of consciousness and aspects of reality that are non-material and beyond our day-to-day normal consciousness, and that the goal of human development is to connect with these realities, one can reduce connection to activation of brain neurology and leave it at that (Andew Newberg et al., 2001; Andrew Newberg, 2006). However, we would argue that failure to recognize this basic truth of human existence and experience necessarily hamstrings the eupsychian project by excluding the possibility of this highest attainment of human health, wellbeing, and development. 
And that is the Circle of Seven Essential Needs. We think the circular presentation of human needs is superior to the pyramid and other geometric representations for several reasons. For one, including all the needs into a single icon prevents individuals from ignoring those aspects of the theory, like transcendence or truth, that make them uncomfortable. For two, including all the basic needs in a circle bakes in the space required for individual flexibility and cultural variability of needs satisfaction. For three, arranging essential needs into a circle allows greater space for the evolution of thinking on needs than the pyramidal representation. Additional needs may be theorized and subtracted or added as necessary without undermining the basic icon. Four, and in line with criticisms in the literature, prepotency is de-emphasized by a circular representation. This does not diminish the significance of any of the needs. Rather, it highlights the critical fact, stated by Maslow on numerous occasions, that "deficits...must ordinarily be fairly well satisfied before real individuality can develop fully" (A. H. Maslow, 1968a, p. 33). In other words, all basic needs have to be sufficiently satisfied before inner needs for alignment and connection can be adequately met. If hungry, that need must be satiated. If you need a hug, that need needs to be satisfied, sometimes even before you eat. If you need support to develop selfesteem, that need needs to be satisfied. If you need help with a sense of power, that need needs to be satisfied. If you need a safe and stable environment, that needs to be satisfied. These needs do not emerge only when physiological needs are satisfied. A hungry child has the same need for safety, security, love, truth, etc. as a child who has a full belly. Finally, organizing the needs into a circle strips the elitism and hierarchy implied (and often stated) in Maslow's theory. Rather than providing an icon that implies only the more evolved may attain the highest heights, as 
Maslow sometimes said (A. H. Maslow, 1970), the circle represents clearly that anybody can align and connect and that the only prerequisite is that basic needs be sufficiently met.

\section{Eupsychian Theory}

Moving forward, it is important to understand that the circle of essential needs represents not merely a theory of motivation. The circle provides the core theoretical statement of Eupsychian psychology, which Maslow defined as a psychology of how to develop a healthy and supportive society capable of generating healthy happy humans (A. H. Maslow, 1968a; Abraham H. Maslow, 1965, p. 149). In this context, the Circle of Seven Essential Needs is a) a statement of the ultimate goal of human development, which is the development of the capacity for healthy and stable connection to something more than the atomized, individualistic, self, as well as b) a statement of the basic social infrastructure needed to actuate connection. The basic social infrastructure is simple to conceptualize. In order to create healthy and happy humans, a society must be geared towards meeting all essential needs.

To gain a fuller appreciation of the integrative Eupsychian theory it represents, and to get a better sense of how to move research and theorization forward, a few more comments reflecting the core of Eupychian Theory are in order. We start with statements closest to Maslow's theorization (statements one through four) and move beyond with our own thinking on Eupsychian Theory.

\section{Eupsychian Theory}

1. Full health and full human development requires reasonable satisfaction of all essential needs. Satisfaction of basic needs ensures basic physiological, emotional, and 
psychological health. It provides the scaffolding that allows one to explore, develop, align, and connect. As Maslow repeatedly said, "The main path to health and self-fulfillment... is via basic need gratification rather than via frustration" (A. H. Maslow, 1968a, p. 199)." Satisfaction of physiological needs keep the body and mind healthy. Satisfaction of cognitive needs for truth and understanding provide the foundation for existing in and aligning with reality. Satisfaction of emotional and psychological needs give us the ego strength to operate in the world and pursue alignment and connection. An individual who struggles with selfesteem is more likely to connect with toxic groups when those groups offer protection, belonging, acceptance, etc. Someone with low self-esteem and diminished sense of power is more likely to "go along to get along" in order to accomplish inclusion and acceptance. Someone with low self-esteem may have a hard time dealing with powerful connection experiences (i.e. peak experiences, transcendent events, mystical experiences, etc.). Finally, someone who lives in unsafe, chaotic, and filthy environments may spend more energy on defense (e.g., fending off parental assaults), offense (rebelling against unnecessary restrictions), and escape (self-medication, anesthetizing behaviours, distractions, avoidance) than on achieving alignment and developing connection.

2. Psychopathology and "evil" results from the frustration, corruption, or violent suppression of our essential needs (A. H. Maslow, 1970, p. 1969). "A basically thwarted man may actually be defined as a 'sick' man" (A. H. Maslow, 1943a, p. 395). "In our society the thwarting of these needs is the most commonly found core in cases of maladjustment and more severe psychopathology " (A. H. Maslow, 1943a, pp. 381-383). "Destructiveness, sadism, cruelty, malice, etc., seem so far to be not intrinsic but rather they seem to be violent 
reactions against frustration of our intrinsic needs, emotions and capacities" (A. H. Maslow, 1968a, p. 3). "We do know, however, that out of the search for fulfillment of a basic needtake love in the child for example-can come evil. The child, wanting his mother's exclusive love, may bash his little brother over the head in hopes of getting more of it. What we call evil or pathological may certainly arise from, or replace, something good. Another example is the little squabbles among children; all the fighting they do about who should do what, about dividing up the chores, ultimately can be seen as a distorted expression of a very powerful need fairness and justice" (A. Maslow, 1961, p. 8).

3. Satisfaction of human needs is inherently social, As Maslow says, "Sick people are made by a sick culture; healthy people are made possible by healthy culture.” (A. H. Maslow, 1968a, p. 6). Or "I can say much more firmly than I ever did, for many empirical reasons, that basic human needs can be fulfilled only by and through other human beings, i.e., society" (A. H. Maslow, 1964). In other words, we need people and not products. In order to satisfy physiological needs, we need farmers, carpenters, electricians, engineers, and so on. In order to meet emotional and psychological needs, we need nurturing caregivers, teachers, and other professional helpers. In order to meet cognitive needs, we need authors, scientists, teachers, parents, priests, etc. Even our higher needs for alignment and connection require the assistance of others. The idea that we are an individual going on some form of hero's journey (Campbell, 2008) of self-actualization is a horrible and culturally biased misrepresentation of the actual process of human development. Instead of providing a rubric for healthy development, it helps instantiate economic, social, political, and psychological realities required by the Capitalist System. 
4. Satisfaction of human needs is difficult and requires careful and sustained support from families and institutions geared towards satisfaction of essential needs and not, for example, accumulating wealth or consumer purchase. As Maslow said, "Culture is definitely and absolutely needed for their actualization; but also culture can fail to actualize them, and indeed this is just what most known cultures actually seem to do and to have done throughout history." (A. H. Maslow, 1967, p. 114). We need a society that "approves of human nature and therefore actively fosters its fullest growth." (A. H. Maslow, 1967, p. 115). We need a society that recognizes that the inner nature is "not strong," but "weak and delicate and subtle and easily overcome by habit, cultural pressure, and wrong attitudes toward it" (A. H. Maslow, 1968a, p. 4). Conditions have to be setup so needs may be met and development may proceed apace. Parents and others have to pay constant attention to the individual if the "delicate task" of creating "good growth" is to be achieved (A. H. Maslow, 1954, p. xviii). In line with this we should note that fully satisfying human needs in a "good society" is a massive task. It is not something that just one person, like a mother, or a friend, or a teacher, can do. The old saying goes, "It takes a village to raise a child." In fact, that does not go nearly far enough. Meeting all the essential human needs requires participation of every single adult and every single institution on the planet. It takes a healthy and developed planet with advanced political and economic forms to properly raise a child.

5. Capitalist society is incompatible with full human development. Although the productive, economic, and administrative expertise that develops under capitalism may contribute to global satisfaction of certain basic needs, the economic, ideological, and labour requirements of capitalism require the subversion and distortion of those aspects of human 
nature that do not fit with the requirements of the Capitalist system. Maslow clearly recognized this, especially in his later work (A. Maslow, 1961; A. H. Maslow, 1970; Abraham H. Maslow, 1965). Further, one does not have to go very deep into the sociological literature to see how Capitalism gears political, education, economic, religious, corporate, media, and legal institutions towards the creation of compliant worker bees.

6. Because full human development is incompatible with Capitalist exploitation, capitalists create and propagate a Toxic Socialization process deliberately designed to neglect human needs, undermine human potential, and distort human nature. Capitalists do this because healthy, aligned, and connected individuals resist insertion in the System and are ultimately threats to the capitalist status quo (Sosteric, 2018b, 2021). Aligned and connected individuals are motivated by "metamotivations" and b-values like "truth, beauty, newness, uniqueness, justice, compactness, simplicity, goodness, neatness, efficiency, love, honesty, innocence, improvement, orderliness, elegance, growth, cleanliness, authenticity, serenity, peacefulness, and the like" (A. H. Maslow, 1967, p. 101). Individuals who are aligned and connected have sense of power and autonomy (A. H. Maslow, 1968a, p. 153) that is absent from the general population and that makes it much harder to exploit and control them. Aligned and connected people work for truth, justice, and the emancipation of the planet and do not support exploitative regimes.

7. Toxic socialization is a violent, neglectful, chaotic process characterized by indoctrination and destruction of primary attachments (Sosteric \& Ratkovic, 2016). Violence includes emotional, psychological, and physical violence (spanking, shaming, incarceration, punishment, name calling, etc.). Neglect is neglect of the seven essential needs. 
Indoctrination involves the propagation of untruths about human nature, human society, and the System designed to facilitate the creation of passive Capitalist cogs willing to sacrifice their entire life to labouring within an exploitative system of accumulation. The distortion/destruction of primary attachments facilitates this insertion by a) breaking family bonds that might otherwise protect children from the "real" world and b) throwing individuals out into the "real world" as early as possible to work and consume their lives away. In this context, toxic socialization is characterized by hurried development and premature ejection into adulthood. Note that recent neurological research indicates the human brain continues to develop well into one's thirties (Edwards, 2010).

\section{All institutions within a Capitalist rubric implement a toxic socialization process. A}

family that hits their children or engages in any form of psychological or emotional violence is a family that practices toxic socialization. A religion that encourages passive acceptance of patriarchal authority, that encourages violence against children ("spare the rod and spoil the child"), or that propagates spiritually flavored ideology (Sosteric, Unpublished), is a religion that implements toxic socialization. An educational system that forces children into streams and educates them differently depending on their presumed destination in the workforce (Anyon, 1980), an educational system that encourages various forms of violence, including the violence of hierarchical grading, the violence of emotional and psychological assault (Sosteric, 2013), and the violence of domination and competition (Kohn, 1986), is an education system that implements toxic socialization. Note that the colonial system, as implemented in residential schools, is the pinnacle and model of toxic socialization. Residential schools implemented a violent, neglectful and chaotic process that broke primary 
attachments and filled children with capitalist-friendly ideologies within a hierarchical and authoritarian framework.

9. Toxic socialization creates unhealthy, dissatisfied, unaligned, disconnected, and easy to manipulate human beings, a fact that is confirmed if one merely looks at the prevalence of depression and other forms of mental illness in "modern" and "advanced" capitalist society, and the ease with which elites manipulate damaged individuals (Sosteric, 2017). Damage begins at birth with the forced assignment of binary gender, continues through infancy and early childhood in sub-optimal environments characterized by toxic socialization, and culminates in an adult human that is not the pinnacle of human potential, but a stripped-down, disconnected, unaligned, and desiccated husk suitable for insertion into the Capitalist system.

10. Speaking of the pathologically generated by toxic socialization, psychologically, emotionally, and neurologically speaking, there are three modes of ego operation, Deficit Mode, Defense Mode (pathological modes), and Growth Mode.

Defense Mode is a mode of operation in which a substantial portion of available biological energy goes towards protecting oneself from assault and chaos.

Deficit mode is a mode of ego operation where a substantial portion of available energy goes towards attempting to meet unmet needs.

Growth Mode is a mode of operation where a substantial portion of available energy goes towards healing, alignment, and connection. As Maslow said, humans have a natural built in ability to heal, a "will to health" (A. H. Maslow, 1968a, p. 193), or a will to satisfy needs, 
align, and connect. This will and ability, this growth mode, is undermined and even subverted (see learned helplessness) when the individual endures toxic environments.

For reasons that should be fairly clear at this point, individuals who operate in deficit and defense mode are a boon for consumer capitalism that depends for its operation on atomized, compliant, easy to manipulate workers driven to achieve (i.e., work) and consume. On the other hand, individuals who operate in Growth Mode are a problem for the System, since they are focused on higher values and tend to reject authority, consumerism, and the capitalist ethos (A. H. Maslow, 1971).

11. Chronic exposure to the violence, neglect, indoctrination, and chaos of Toxic Socialization is cumulative and leads to increasingly pathological outcomes.

12. There are three levels of deficit/defense pathology, coping, neurosis, and psychosis. One starts by coping, but when coping is not enough, one transitions to neurotic and finally psychotic defense and indulgence. In the worst cases, those who experience years and decades of toxicity may move towards psychosis and the development of the type of "deplorable," hate-filled psychopathy that, when combined with old energy archetypes (Sosteric, Unpublished), allows elites to weaponize the masses (Sosteric, 2018c).

1. Coping: When individuals are confronted with a toxic socialization process, they try to cope. Coping represents psychological, emotional, cognitive, and behavioural adaptations designed to help the individual defend against threat, alleviate confusion and chaos, and gratify, albeit in a toxic way, essential needs. A child who is not getting enough love and attention becomes needy and clingy (Deficit mode). A child 
who is experiencing violence in the home copes by escaping (Defense mode) or becomes a bully as a way of taking out the anger and resentment, or fending off possible assault (Defense Mode). Somebody with damaged self-esteem copes by becoming self-aggrandizing (Defense mode), or by seeking constant approval (Deficit Mode). In cases of chronic violence and chaos, individuals become "safety-seeking" (A. H. Maslow, 1943a, p. 39) organisms (Defense mode). The individual who joins a cult may be looking for ways to alleviate confusion (cults claim to provide answers) or fill unmet needs for belonging (both Deficit and Defense mode). The individual who hates others may be looking for inclusion in a group, even if that group is a hate group (Deficit mode).

2. Neurosis: When the experience of toxic socialization is chronic and severe, coping eventually transits into neurosis. Neuroses are serious and persistent psychological, emotional, cognitive, and behavioural adaptations that undermine healthy human function. As with an individual's efforts to cope, neuroses are designed to satisfy unmet needs and defend against violence, chaos, and abuse.

Neurosis (and psychosis for that matter) are ultimately diseases of trust and fear. We mistrust the environment and other people so we build neurotic defenses. We fear the emptiness that comes from neglect and failure to satisfy our essential needs. We fear the violence directed at us from those teachers, parents, priests, and adults who are more powerful than us. We fear the confusion and disorganization sowed by indoctrination. The individual who compulsively and obsessively cleans may be neurotically coping with a childhood of violence where the only "out" was to keep 
busy cleaning the house, or may be acting to prevent the emergence of uncomfortable thoughts and emotions, or engages in the act in order to get noticed, rewarded, conditional regard or love. As Maslow said, they try to arrange the world so that anything unexpected ... cannot possibly occur" (A. H. Maslow, 1954, p. 43) The individual who has an "attention deficit" and who is constantly scanning the environment may not have an attention deficit but a neurotic need to scan the environment for the next incoming assault.

3. Psychosis: When conditions are toxic enough, and when the toxicity persists for years, even decades, neurosis can transit into psychosis. Psychosis represents neurotic methods of coping that have become disconnected from reality, probably because disconnection from reality is the only reasonable out. Psychosis may also represent organic damage to the physical body, persistent neurochemical imbalances, and reprogrammed instinctoid responses (Sosteric \& Ratkovic, 2016). Psychosis represents significant damage and there are significant challenges in conceptualizing and implementing healing methodologies. In this regard, psychedelic therapies with connection supplements that encourage neurogenesis may be the best hope.

13. Healing involves getting the client into growth mode. As Maslow said, psychotherapy (i.e. psychological healing) is "Any means of any kind that helps to restore the person to the path of self-actualization and of development along the lines that his inner nature dictates"(A. H. Maslow, 1970, p. 270). An individual in growth mode has the energy and supports necessary for healing, alignment, and connection. 
Healing is a topic for its own paper. Here we will simply say that healing involves three things. Number one, healers help the client understand the nature of the damage accrued so they can take appropriate actions to heal, align, and connect. Number two, healers help heal the neurological, psychological, cognitive, and emotional damage done by toxic socialization. Finally, healers help the client create environmental conditions that satisfy the basic needs and that support and nurture alignment and connection.

\section{Conclusion}

In this paper, we have examined Maslow's theory of motivation, arguing that Maslow and others were on their way to developing an integrative theory, but that this development was hijacked by the imposition of ideologically rooted misrepresentation of Maslow's theory. For various reasons, the ideologically rooted pyramid and the stripped-down theorization continues to be used by scholars and the general pubic. In this article, we suggest ejecting the pyramid and recovering Maslow's Eupsychian theory. We suggested an alternate icon, the Circle of Seven Essential Needs, and provided some preliminary theoretical statements supporting this selection. Building on the circle, we note that actualization of full human potential requires reasonable satisfaction of all essential needs, and that psychopathology and evil results from a toxic socialization process. We note Capitalism, while it has been a boon to the satisfaction of physiological needs, undermines human potential and damages the human being. What humans need now is a society focused not on profit and accumulation, but one focused on meeting all essential needs and healing the damage done by Capitalism. 


\section{References}

Anburaj Balraj, N. (2017). Foundational Elements of Maslow's Hierarchy of Needs and Jesus Christ's Teachings of Human Need Management. Catalyst, 15(1), 77-88. Academic Search Index.

Anyon, J. (1980). Social Class and the Hidden Curriculum of Work. Journal of Education, 162(1).

Aron, A. (1977). Maslow's Other Child. Journal of Humanistic Psychology, 17(2), 9. https://doi.org/ $10.1177 / 002216787701700203$

Ballard, J. A. (2006). The diffusion of Maslow's motivation theory in management and other disciplines. Academy of Management Annual Meeting. https://www.researchgate.net/publication/320806774_The_diffusion_of_Maslow's_moti vation_theory_in_management_and_other_disciplines

Blackstock, C. (2011). The Emergence of the Breath of Life Theory. Journal of Social Work Values \& Ethics, 8(1), 13-28. SocINDEX with Full Text.

Blavatsky, H. P. (1889). The Key to Theosophy: A Clear Exposition Based on the Wisdom Religion of All Ages. Theosophical University Press.

Bodhi, B. (Ed.). (2005). In the Buddha's Words: An Anthology of Discourses from the Pali Canon. Wisdom Publications.

Bourgeault, C. (2015). The Gospel of Mary Magdalene. Parabola.

Bouzenita, A. I., \& Boulanouar, A. W. (2016). Maslow's hierarchy of needs: An Islamic critique. Intellectual Discourse, 24(1). Directory of Open Access Journals. http://Osearch.ebscohost.com.aupac.lib.athabascau.ca/login.aspx?

direct=true\&db=edsdoj\&AN=edsdoj.408c7302c6824167booeadb5581fa68e\&site=eds-live

Boyce, M. (1996). A History of Zoroastrianism: Volume One The Early Period. E. J. Brill. 
Bridgman, T., Cummings, S., \& Ballard, J. (2019). Who Built Maslow's Pyramid? A History of the Creation of Management Studies' Most Famous Symbol and Its Implications for Management Education. Academy of Management Learning \& Education, 18(1), 81-98. Business Source Complete.

Broker, I. (1983). Night Flying Woman: An Ojibway Narrative. Minnesota Historial Society Press. https://amzn.to/2UFatVZ

Bucke, R. M. (2009). Cosmic Consciousness. E.P. Dutton.

Buttle, F. (1989). The Social Construction of Needs. Psychology and Marketing, 6(3), 197.

Campbell, J. (2008). The Hero with a Thousand Faces. Yogi Impressions.

Carpenter, E. (1921). The Art of Creation: Essays on the Self and Its Powers. Amazon. https://amzn.to/2OSE3lu

Christian Montag, Cornelia Sindermann, David Lester, \& Kenneth L. Davis. (2020). Linking individual differences in satisfaction with each of Maslow's needs to the Big Five personality traits and Panksepp's primary emotional systems. Heliyon, 6(7). Directory of Open Access Journals. https://doi.org/10.1016/j.heliyon.2020.e04325

Crandall, A., Powell, E. A., Bradford, G. C., Magnusson, B. M., Hanson, C. L., Barnes, M. D., Novilla, M. L. B., \& Bean, R. A. (2020). Maslow's Hierarchy of Needs as a Framework for Understanding Adolescent Depressive Symptoms Over Time. Journal of Child \& Family Studies, 29(2), 273-281. CINAHL Plus with Full Text. https://doi.org/10.1007/s10826-019$01577-4$

Cross, T. (2007). Through indigenous eyes: Rethinking theory and practice. Conference of the Secretariat of Aboriginal and Islander Child Care.

Davis, K. (1957). Human relations in business. McGraw-Hill. 
Deloria, V. Jr. (2003). God is Red: A Native View of Religion. Fulcrum Publishing.

Dewsbury, D., Benjamin, L. T., \& Wertheimer, M. (Eds.). (2012). Abraham H. Maslow: Reconnaissance for Eupsychia. In Portraits of Pioneers in Psychology: Vol. VI (pp. 255-271). American Psychological Association.

Edwards, L. (2010). Brain is not fully mature until 30 s and 40s. Medical Express.

Ernst, C. W. (1997). The Shambhala Guide to Sufism. Shambhala Publications. https://amzn.to/2SoFmun

Griffen, D. R. (1988). Introduction: The Reenchantment of Science. In D. R. Griffen (Ed.), The Reenchantment of Science (pp. 1-46). SUNY Press.

Habib, R. (1993). Modernising vs Westernizing the social sciences: The case of psychology. In A. M. Elmessiri (Ed.), Epistemological bias in the physical and social sciences. IIIT.

Heylighen, F. (1992). A cognitive-systemic reconstruction of Maslow's theory of selfactualization. Behavioral Science, 1, 39. Gale Academic OneFile.

Hoffman, E. (1999). The Right to be Human. McGraw Hill.

Hoffman, Edward. (1999). The Right to be Human: A Biography of Abraham Maslow. McGraw Hill.

Ikbal, A. S. (2000). Islamic Sufism. Tractus Books.

James, W. (1982). The Varieties of Religious Experience: A Study of Human Nature. Penguin. https://amzn.to/2l4UyR7

Jie Guo, Dongdong Weng, Zhenliang Zhang, Yue Liu, \& Yongtian Wang. (2019). Evaluation of Maslows Hierarchy of Needs on Long-Term Use of HMDs - A Case Study of Office Environment. 2019 IEEE Conference on Virtual Reality and 3D User Interfaces (VR), Virtual Reality and 3D User Interfaces (VR), 2019 IEEE Conference On, 948-949. IEEE Xplore Digital Library. https://doi.org/10.1109/VR.2019.8797972 
Kalisch, I. (2006). Sepher Yezirah: A Book on Creation. The Book Tree. https://amzn.to/2WPnklN

Kenrick, D. T., Griskevicius, V., Neuberg, S. L., \& Schaller, M. (2010). Renovating the Pyramid of Needs: Contemporary Extensions Built Upon Ancient Foundations. Perspectives on Psychological Science, 5(3), 292-314. CINAHL Plus with Full Text. https://doi.org/10.1177/1745691610369469

Kohn, A. (1986). No Contest: The Case Against Competition. Houghton Mifflin. https://amzn.to/2X8g7ol

Koltko-Rivera, M. E. (2006). Rediscovering the Later Version of Maslow's Hierarchy of Needs: Self-Transcendence and Opportunities for Theory, Research, and Unification. Review of General Psychology, 10(4), 302-317.

Kuo-Shu Yang. (2003). Beyond Maslow's Culture-Bound Linear Theory: A Preliminary Statement of the Double-Y Model of Basic Human Needs. Nebraska Symposium on Motivation (University of Nebraska Press), 49, 175-255. Supplemental Index.

Laszlo, E. (2006). Science and the Reenchantment of the Cosmos. Inner Traditions.

Lawlor, R. (1991). Voices of the First Day: Awakening in the Aboridinal Dreamtime. Inner Traditions.

Loh, D., Schapper, J., \& Wrathall, J. (2000). The maslow revival: Maslow's hierarchy of needs as a motivational theory. [Working Paper].

Lussier, K. (2019). Of Maslow, motives, and managers: The hierarchy of needs in American business, 1960-1985. Journal of the History of the Behavioral Sciences, 4, 319. Gale Academic OneFile. https://doi.org/10.1002/jhbs.21992

Maslow, A. (1961). Eupsychia-The Good Society. Journal of Humanistic Psychology, 1(2), 1.

Maslow, A. H. (1943a). A Theory of Human Motivation. Psychological Review, 50(4), 370-396. 
Maslow, A. H. (1943b). Preface to Motivation Theory. Psychosomatic Medicine, 5(1), 85. edb.

Maslow, A. H. (1954). Motivation and Personality. Harper \& Row. https://amzn.to/2OSRmlX

Maslow, A. H. (1964). Religions, Values, and Peak Experiences. Ohio State University Press. https://amzn.to/2U2Rhgq

Maslow, A. H. (1967). A theory of metamotivation: The biological rooting of the value-life. Journal of Humanistic Psychology, 7, 93-127.

Maslow, A. H. (1968a). Towards a Psychology of Being (2nd Edition). Van Nostrand Reinhold Company.

Maslow, A. H. (1968b). Some Fundamental Questions that Face the Normative Social Psychologist. Journal of Humanistic Psychology, 8(2), 143. Complementary Index.

Maslow, A. H. (1969). The Farthest Reaches of Human Nature. The Journal of Transpersonal Psychology, 1(1), 1-9.

Maslow, A. H. (1969). Various Meanings of Transcendence. Journal of Transpersonal Psychology, $1(1), 56-66$.

Maslow, A. H. (1970). Motivation and Personality (2nd ed.). Harper \& Row. https://amzn.to/2OSRmlX

Maslow, A. H. (1971). The Farther Reaches of Human Nature. Viking. https://amzn.to/2FWovpX

Maslow, A. H. (2012). The “Core-Religious" or “Transcendent” Experience. In John White (Ed.), The Highest State of Consciousness (pp. 339-350). Doubleday.

Maslow, Abraham H. (1965). Eupsychian management: A journal. Richard D. Irwin Inc. \& The Dorsey Press. https://archive.org/details/eupsychianmanageoooomasl/ 
Maslow, Abraham H. (1966). The Psychological Aspect: Desacrilization. American Journal of Psychoanalysis, 26(2), 148-157.

McCleskey, J. A., \& Ruddell, L. (2020). Taking a Step Back-Maslow's Theory of Motivation: A Christian Critical Perspective. Journal of Biblical Integration in Business, 23(1), 6. Complementary Index.

McDermid, C. D. (1960). How Money motivates Men. Business Horizons, 3(4), 93-100. ScienceDirect.

Mernissi, F. (1991). Women and Islam: An Historical and Theological Inquiry (M. J. Lakeland, Trans.). Basil Blackwell.

Neher, A. (1991). Maslow's Theory of Motivation: A Critique. Journal of Humanistic Psychology, 31(3), 89-112. https://doi.org/10.1177/0022167891313010

Nevis, E. C. (1983). Cultural assumptions and productivity: The United States and China. Sloan Management Review, 24(3), 17-29. MEDLINE.

Newberg, Andew, d'Aquile, E., \& Rause, V. (2001). Why God Won't Go Away: Brain Science and the Biology of Belief. Ballantine Books.

Newberg, Andrew. (2006). The neurobiology of spiritual transformation. In P. Hefner \& J. Koss-Chioino (Eds.), Spiritual Transformation and Healing: Anthropological, Theological, Neuroscientific, and Clinical Perspectives,. Rowman \& Littlefield.

Nicholson, I. A. M. (2001). "Giving up maleness”: Abraham Maslow, masculinity, and the boundaries of psychology. History of Psychology, 4(1), 79-91. APA PsycArticles. https://doi.org/10.1037/1093-4510.4.1.79 
Peterson, C., \& Park, N. (2010). What Happened to Self-Actualization? Commentary on Kenrick et al. (2010). Perspectives on Psychological Science: A Journal of the Association for Psychological Science, 5(3), 320-322. MEDLINE. https://doi.org/10.1177/1745691610369471

Philo of Alexandira. (2014). Complete Works of Philo of Alexandria. Delp Classics.

Poirier, T. I., \& Devraj, R. (2019). Pharmacy in an Improved Health Care Delivery Model Using Maslow's Hierarchy of Needs. American Journal of Pharmaceutical Education, 83(8), 16641667. Academic Search Complete.

Soper, B., Milford, G. E., \& Rosenthal, G. T. (1995). Belief When Evidence Does Not Support Theory. Psychology and Marketing, 12(5), 415.

Sosteric, M. (Unpublished). From Zoroaster to Star Wars, Jesus to Marx: The Art, Science, and Technology of Human Manipulation. https://www.academia.edu/34504691

Sosteric, M. (2013). The emotional abuse of our children: Teachers, schools, and the sanctioned violence of our modern institutions. The Socjournal, March.

Sosteric, M. (2017). Trump's manipulation of mass consciousness. The Conversation.

Sosteric, M. (2018a). Everybody has a connection experience: Prevalence, confusions, interference, and redefinition. Spirituality Studies, 4(2). https://www.spiritualitystudies.org/dp-volume4-issue2-fall2o18/files/assets/common/downloads/files/4-2sosteric.pdf

Sosteric, M. (2018b). Mystical experience and global revolution. Athens Journal of Social Sciences, $5(3), 235^{-255}$

Sosteric, M. (2018c). Star Wars is a religion that primes us for war and violence. The Conversation. https://theconversation.com/star-wars-is-a-religion-that-primes-us-forwar-and-violence-89443 
Sosteric, M. (2021). Rethinking the Origins and Purpose of Religion: Jesus, Constantine, and the Containment of Global Revolution. Athens Journal of Social Sciences. https://www.academia.edu/34970150/

Sosteric, M., \& Ratkovic, G. (2016). Toxic Socialization. https://www.academia.edu/25275338/Toxic_Socialization

St. Teresa of Avila. (2007). Interior Castle (Kindle). Dover Publications. https://amzn.to/2GpC7NG

Steeman, T. M. (1975). Church, sect, mysticism, denomination: Periodological aspects of Troeltsch's types. SA. Sociological Analysis, 36(3), 181-204. rfh.

Suzuki, D. T. (1994). An Introduction to Zen Buddhism. Grove Press. https://amzn.to/2Tp6gWG

Swedenborg, E. (2016). New Jerusalem. Swedenborg Foundation. https://amzn.to/2TpJ5vc

Tolstoy, L. (2016). The Kingdom of God Is Within You (Classics To Go) eBook: Leo Tolstoy: Amazon.ca: Gateway (C. Garnett, Trans.). CreateSpace. https://amzn.to/2Dg2jtj

Townsend, P., \& Wrathall, J. (1997). An Analysis of the Cross-Cujltural Transferability of Western Motivation Theories to the Developing Eastern, China Region [Working Paper].

Underhill, E. (2002). Mysticism: A Study in the Nature and Development of Spiritual Consciousness (Kindle). Dover Publications. https://amzn.to/2C91xNY

Wren, D. A. (1972). The evolution of management thought. Ronald Press. 